\title{
Estimating Static Postural for the Stabilizing Reformation on the Bio Parameter Detector Combination System
}

\author{
Jeong-lae Kim ${ }^{1}$ and Myung Jae $\mathrm{Lim}^{2}$,* \\ ${ }^{1}$ Department of Biomedical Engineering Eulji University, Seoul, Korea \\ ${ }^{2}$ Department of Medical IT and Marketing, Eulji University, Seongnam, Korea \\ jlkim@eulji.ac.kr,lk04@eulji.ac.kr \\ *Corresponding Author:lk04@eulji.ac.kr
}

\begin{abstract}
This study was designed the bio parameter detector combination system of static posture for reformation by the stability. We used a model of bio-sensor combination system on the basis of the static state in the standing posture. To evaluate the condition (Vision, Vestibular, Somatosensory and CNS), we compared the horizontal movement of average derived from the estimated eye open state in the body moving before $\left(\alpha-\mu_{B E N O}\right)$ to horizontal movement of average derived from the estimated eye close state in the body moving before $\left(\alpha-\mu_{B E N C}\right)$. As the model depends on the bio-sensor combination system of body moving, average values of these variation were computed $(0.01 \mathrm{~Hz} \sim 2 \mathrm{~Hz}$, range of Fourier frequency). These systems consist of a data acquisition system for capturing and sending data signal, and to gather a data signal processing, and to control a feedback system. There were evaluated their body sway, and identified to maintain the stability.
\end{abstract}

Keywords: Bio parameter detector combination system, Static Posture, Signal processing, Data acquisition system $u$-Healthcare system

\section{Introduction}

Recently, the modern man needs to supply a special care services through body moving for essential and constantly healthcare from the stable everyday life [1-3]. In order to provide proper healthcare services, it is indeed necessary to monitor their physiological parameters for moving [4-6].

Bio-sensor combination system through posture moving take objective measures of balance responses using more sophisticated, computerized equipment. This equipment can be used to evaluate sensory organization as well as the patient's posture motor performance. Force-plate was referenced to the patient by means of hydraulic mechanism. A printed dot graph tells how well the patient did during each of the four conditions [7]. These measurements are intrinsically variable, and this poses problems when one wishes to compare postural stability between different individuals or for the same individual across different session. However, there was a limited amount of data on the reliability of the quantitative parameters used for characteristic graph [20].

In this study, bio-sensor combination system was developed to integrate a physical multi-signal in order to monitor body parameters, especially those parameter condition such as eye open and close. This system was used to validate the information capability with local data archive to an acquisition system in the area. 


\section{Related works}

\subsection{Component of multi-sensor compound parameter}

Balance was the center of mass to maintain over the base of support. Limits of stability refer to the maximum angle from vertical that can be tolerated without a loss of balance. Body moving can be defined as the stability produced on each side of a vertical axis on the Balance [8-9]. Body balance while sitting down is activated either when there is movement of the center of gravity over the stable limit or body movement in the knee joint. Balance while standing up is activated as the center of gravity moves and shakes over the stable limit [10-12]. The postural control system consists of three main subsystems such as visual, vestibular, and somatosensory [13]. There system relies on parameter relationships to measure body balance. Sensory compound data collects signal using body exercise on the parameter as shown Figure 1.

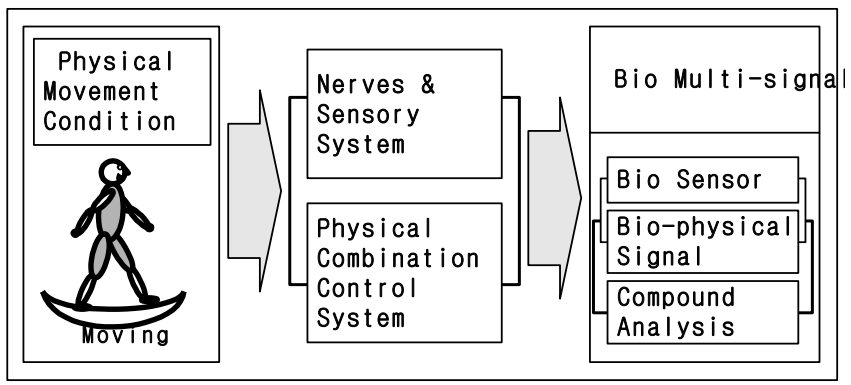

Figure 1. Structure of Bio Multi-signal compound parameter

\subsection{Component of physical parameter and postural analysis}

The control Physical parameter was a posture reforming motion balance during the eye open and eye close, and to add body movement. In addition, for data analysis give an account of a vision, vestibular, somatosensory and central nervous system as shown Figure 2. Analysis data was achieved through frequency [14-16]. Human postural control takes the feedback information in the afferent sensory input information from the visual, vestibular, and somatosensory receptors reporting changes in position and velocity of the body posture [17-19].

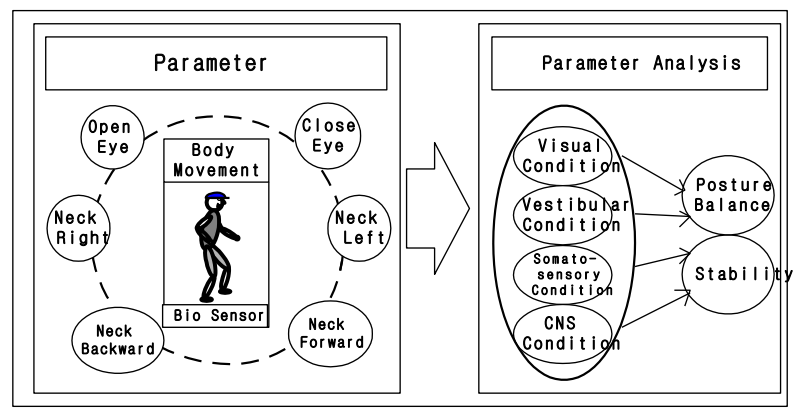

Figure 2. Bio-parameter detector system of Signal processing 


\section{System design}

\subsection{Preprocessing}

The proposed sensor signal system mainly takes care of the static posture in the eye open (EO) and eye close (EC) for monitored subject such as the body movement. This system can keep normally when the body condition is a charm and restfulness and body movement were become abnormal and unstable of body condition.

\subsection{System of physical signal}

In Figure 3, the proposed system are adverted the architecture. The system was divided into two parts such as data acquisition system and signal processing system [21]. The system was designed as to measure body moving from data acquisition system and signal processing system [22]. There (PXI-6251 DAQ, PXI-1409, NI., USA) were acquired signal data to used computer analysis. Feedback system was a signal data of delivering device for correction [23-24]. Measuring signal range was $0.01 \mathrm{~Hz} 2 \mathrm{~Hz}$ or more in Fourier frequency and measured data acquisition system.

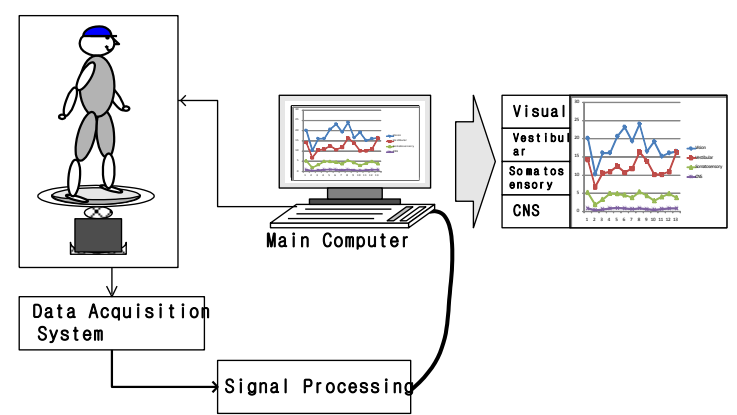

Figure 3. Proposed of a Bio parameter detector combination system for Posture

\section{System Implementation}

\subsection{Database}

The experiments were conducted using our body moving database which is collected from 13 individuals' (including 13 males, Asian race). The age of the participants was between 19 and 28years, and their occupations included university students at our school. The subsection gives an analysis for our proposed system, these parameters and condition are dependent on each other. In order to further understand how to design multi parameter. Several data are performed and results are explained as follows (Table 1).

\section{Comparison of $\mu_{B E N O}, \mu_{B E N C F}, \mu_{A E N O}$ and $\mu_{A E N C}$}

Vision condition was compared for the $\mathrm{Vi}-\mu_{\mathrm{BENO}}$ and $\mathrm{Vi}-\mu_{\mathrm{BENC}}$ (Figure 4$)$. The very smaller average difference between $\mathrm{Vi}-\mu_{\mathrm{BENO}}$ and $\mathrm{Vi}-\mu_{\mathrm{BENC}}$ was with eye open and close of body moving before. The average was slightly greater with $\mathrm{Vi}-\mu_{\mathrm{BENC}}(5.87 \pm 2.54)$. The smaller average difference between $\mathrm{Vi}-\mu_{\mathrm{AENO}}$ and $\mathrm{Vi}-\mu_{\mathrm{AENC}}$ was with eye open and close of body moving after. The average was very smaller with $\mathrm{Vi}-\mu_{\mathrm{AENC}}(0.7 \pm 0.0)$.

Vision condition was compared for body movement with the $\mathrm{Vi}-\mu_{\mathrm{BENO}}$ and $\mathrm{Vi}-\mu_{\mathrm{AENO}}$ (Figure 4). The very smaller average difference between $\mathrm{Vi}-\mu_{\mathrm{BENO}}$ and $\mathrm{Vi}-\mu_{\mathrm{AENO}}$ was with eye 
open of body moving. The average was slightly greater with $\mathrm{Vi}-\mu_{\mathrm{AENO}}(2.55 \pm 1.81)$. The smaller average difference between $\mathrm{Vi}-\mu_{\mathrm{BENC}}$ and $\mathrm{Vi}-\mu_{\mathrm{AENC}}$ was with close of body moving. The average was slightly smaller with $\mathrm{Vi}-\mu_{\mathrm{AENC}}(4.02 \pm 0.73)$.

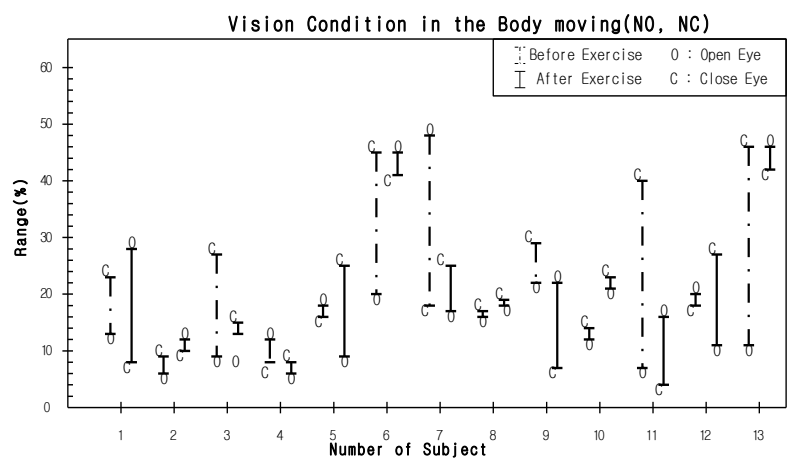

\section{Figure 4. Signal data of Vision condition by the normal moving of Eye open \& Eye close}

Vestibular condition was compared for the $\mathrm{Ve}-\mu_{\mathrm{BENO}}$ and $\mathrm{Ve}-\mu_{\mathrm{BENC}}$ (Figure 5). The slightly smaller average difference between $\mathrm{Ve}-\mu_{\mathrm{BENO}}$ and $\mathrm{Ve}-\mu_{\mathrm{BENC}}$ was with eye open and close of body moving before. The average was very larger with Ve- $\mu_{\mathrm{BENC}}(2.84 \pm 0.61)$. The smaller average difference between $\mathrm{Ve}-\mu_{\mathrm{AENO}}$ and $\mathrm{Ve}-\mu_{\mathrm{AENC}}$ was with eye open and close of body moving after. The average was slightly smaller with $\mathrm{Ve}-\mu_{\mathrm{AENC}}(1.88 \pm 0.61)$. Vestibular condition was compared for body movement with the Ve- $\mu_{\mathrm{BENO}}$ and $\mathrm{Ve}-\mu_{\mathrm{AENO}}$ (Figure 5). The slightly slightly smaller average difference between $V e-\mu_{\mathrm{BENO}}$ and $\mathrm{Ve}-\mu_{\mathrm{AENO}}$ was with eye open of body moving. The average was very larger with $\mathrm{Ve}-\mu_{\mathrm{AENO}}(1.31 \pm 1.15)$. The smaller average difference between $\mathrm{Ve}-\mu_{\mathrm{BENC}}$ and $\mathrm{Ve}-\mu_{\mathrm{AENC}}$ was with close of body moving. The average was very smaller with $\mathrm{Ve}-\mu_{\mathrm{AENC}}(0.35 \pm 0.36)$.

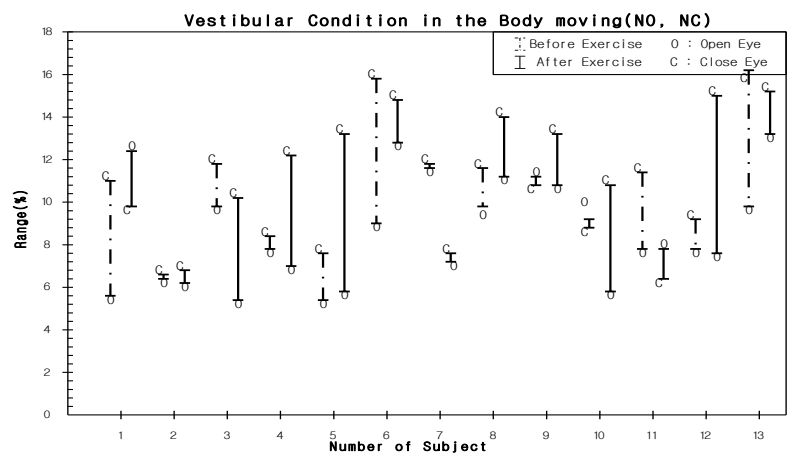

\section{Figure 5. Signal data of Vestibular condition by the normal moving of Eye open \& Eye close}

Somatosensory condition was compared for the So- $\mu_{\mathrm{BENO}}$ and So- $\mu_{\mathrm{BENC}}$ (Figure 6). The slightly smaller average difference between So- $\mu_{\mathrm{BENO}}$ and So- $\mu_{\mathrm{BENC}}$ was with eye open and close of body moving before. The average was slightly larger with So- $\mu_{\mathrm{BENC}}(0.66 \pm 0.24)$. The smaller average difference between So- $\mu_{\mathrm{AENO}}$ and So- $\mu_{\mathrm{AENC}}$ was with eye open and close of body moving after. The average was slightly smaller with So- $\mu_{\mathrm{AENC}}(0.54 \pm 0.49)$. Somatosensory condition was compared for body movement with the So- $\mu_{\mathrm{BENO}}$ and So- $\mu_{\mathrm{AENO}}$ 
(Figure 6). The slightly smaller average difference between So- $\mu_{\mathrm{BENO}}$ and So- $\mu_{\mathrm{AENO}}$ was with eye open of body moving. The average was diminutive larger with So- $\mu_{\mathrm{AENO}}(0.3 \pm 0.22)$. The smaller average difference between So- $\mu_{\mathrm{BENC}}$ and So- $\mu_{\mathrm{AENC}}$ was with close of body moving. The average was diminutive smaller with So- $\mu_{\mathrm{AENC}}(0.18 \pm 0.47)$.

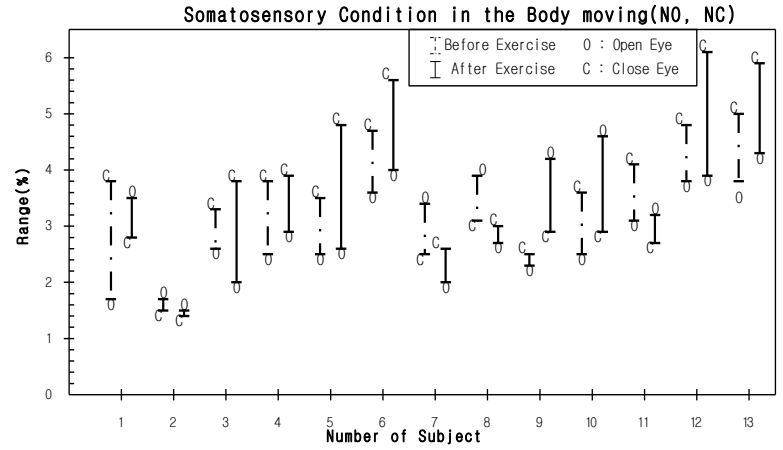

Figure 6. Signal data of Somatosensory condition by the normal moving of Eye open \& Eye close

CNS condition was compared for the $\mathrm{C}-\mu_{\mathrm{BENO}}$ and $\mathrm{C}-\mu_{\mathrm{BENC}}$ (Figure 7 ). The diminutive smaller average difference between $\mathrm{C}-\mu_{\mathrm{BENO}}$ and $\mathrm{C}-\mu_{\mathrm{BENC}}$ was with eye open and close of body moving before. The average was slightly larger with $\mathrm{C}-\mu_{\mathrm{BENC}}(0.12 \pm 0.03)$. The smaller average difference between $\mathrm{C}-\mu_{\mathrm{AENO}}$ and $\mathrm{C}-\mu_{\mathrm{AENC}}$ was with eye open and close of body moving after. The average was diminutive with $\mathrm{C}-\mu_{\mathrm{AENC}}(0.15 \pm 0.13)$. CNS condition was compared for body movement with the $\mathrm{C}-\mu_{\mathrm{BENO}}$ and $\mathrm{C}-\mu_{\mathrm{AENO}}$ (Figure 7 ). The diminutive average difference between $\mathrm{C}-\mu_{\mathrm{BENO}}$ and $\mathrm{C}-\mu_{\mathrm{AENO}}$ was with eye open of body moving. The average was tiny larger with $\mathrm{C}-\mu_{\mathrm{AENO}}(0.09 \pm 0.01)$. The smaller average difference between $\mathrm{C}-\mu_{\mathrm{BENC}}$ and $\mathrm{C}-\mu_{\mathrm{AENC}}$ was with close of body moving. The average was tiny smaller with $\mathrm{C}-\mu_{\mathrm{AENC}}(0.12 \pm 0.11)$.

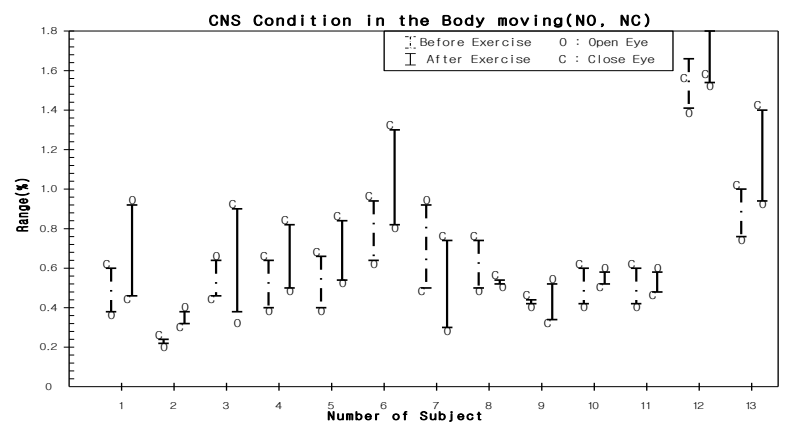

Figure 7. Signal data of CNS condition by the normal moving of Eye open \& Eye close

Table 1. Average static body movement difference measures for various Vision(Vi $\left.\mu_{A v g}\right)$, Vestibular(Ve $\left.\mu_{A v g}\right)$, Somatosensory(So $\left.\mu_{A v g}\right), C N S\left(C \mu_{A v g}\right)$ condition in standing state. Presentation of body moving of before and after with eye open(NO) and eye close(NC).(Average of $\mu_{\mathrm{BENO}}, \mu_{\mathrm{BENC}}, \mu_{\mathrm{BENO}}$, and $\left.\mu_{\mathrm{AENO}}\right)$ 


\begin{tabular}{lcccc}
\hline$\mu_{\text {BENO }}$ & $18.08 \pm 10.61$ & $8.2 \pm 2.21$ & $2.92 \pm 0.76$ & $0.57 \pm 0.32$ \\
$\mu_{\text {BENC }}$ & $23.95 \pm 13.15$ & $11.04 \pm 2.82$ & $3.58 \pm 1$ & $0.69 \pm 0.35$ \\
$\mu_{\text {AENO }}$ & $20.63 \pm 12.42$ & $9.51 \pm 3.36$ & $3.22 \pm 0.98$ & $0.66 \pm 0.33$ \\
$\mu_{\text {AENC }}$ & $19.93 \pm 12.42$ & $11.39 \pm 3.18$ & $3.76 \pm 1.47$ & $0.81 \pm 0.46$ \\
\hline
\end{tabular}

\section{Performance evaluation}

As shown in Figure 8, the performance evaluation results of the normal moving of eye open and eye close. On the posture of body showed difference to the body condition. Their situation presents the relation between before exercise and after exercise. We can be ensured that the body stable in time.

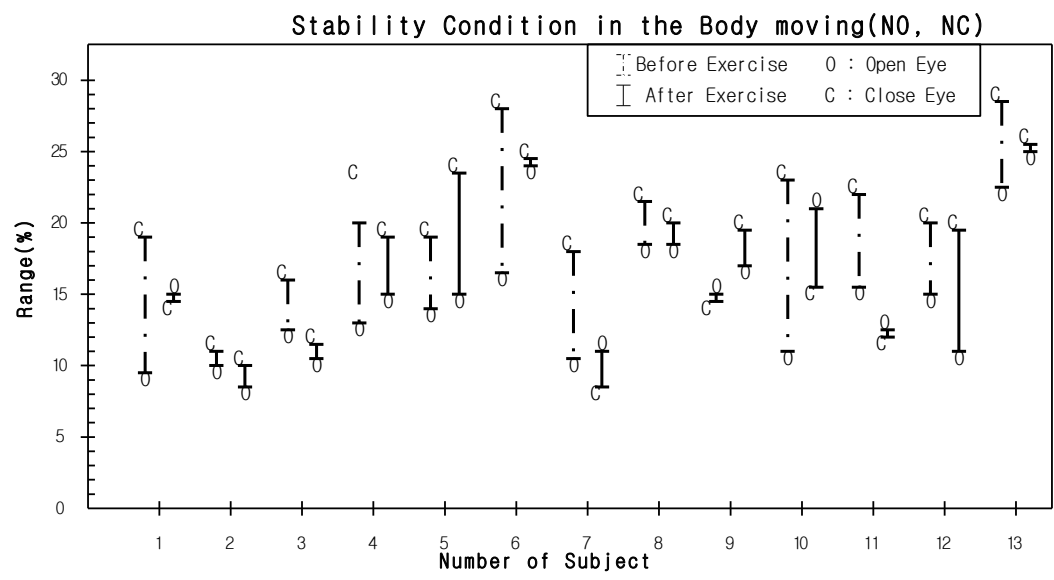

Figure 8. Signal data of Stability by the normal moving of Eye open \& Eye close

\section{Conclusion and Further studies}

In this paper, we used a model of bio parameter detector combination system on the basis of the static state in the standing posture. To evaluate the condition (Vision, Vestibular, Somatosensory and CNS), we compared the horizontal movement of average derived from the estimated eye open state in the body moving before $\left(\alpha-\mu_{\mathrm{BENO}}\right)$ to horizontal movement of average derived from the estimated eye close state in the body moving before $\left(\alpha-\mu_{\mathrm{BENC}}\right)$. And, we compared the horizontal movement of average derived from the estimated eye open state in the body moving after $\left(\alpha-\mu_{\mathrm{AENO}}\right)$ to horizontal movement of average derived from the estimated eye close state in the body moving after $\left(\alpha-\mu_{\mathrm{AENC}}\right)$. As the model depends on the bio-sensor combination system of body moving, average values of these variation were computed $(0.01 \mathrm{~Hz} \sim 2 \mathrm{~Hz}$, range of Fourier frequency). Each average values differences observed with $\mu_{\mathrm{BENO}}, \mu_{\mathrm{BENC}}, \mu_{\mathrm{AENO}}$ and $\mu_{\mathrm{AENC}}$. The smaller average differences between $\mu_{\mathrm{BENO}}$ and $\mu_{\mathrm{BENC}}$ observed with body moving before. The small differences between the preservation confirm the balance for standing position, and the stability of body sway on the eye open and close.

The smaller average differences between $\mu_{\mathrm{BENO}}$ and $\mu_{\mathrm{AENO}}$ observed with body moving before. The small differences between the vision maintenance confirm the balance for 
standing position, and the stability of body sway on the eye open and close. Concerning the body movement of before and after, the validation of vision condition confirms that they are inadequate for static tasks.

The average values of the state of the before body movement was larger than state of the after body movement for the EO and EC condition. Thus, the confirmation of the technique used for the EO and EC condition would be valid for static posture. Finally, the confirmation of the results demonstrate that the vision, vestibular, somatosensory and CNS condition.

This method for evaluating static posture state in a standing position appears reliable and stable. Moreover, with reasonable approximation, this system can be considered of the sensory system of body and of the body sway acquisition system. And it is based on the static position, thereby providing a stable system for the estimating dynamic posture.

\section{Acknowledgements}

This article is a revised and expanded version of a paper entitled [Estimating of Bio signal compound system] presented at International Symposium on Advanced and Applied Convergence held on November 14-16, 2013 at Seoul, Korea. This work was supported by the Bio-Meditech Regional Innovation Center at Eulji University, under the Regional Innovation Center Program(BMRIC) of Ministry Of Trade, Industry and Energy.

\section{References}

[1] M. Alwan, D. C. Mack, S. Dalal, S. Kell, B. Turner and R. A. Felder, "Impact of passive in-home health status monitoring technology in home health: outcome pilot", In: Proceedings of the 1st distributed diagnosis and home healthcare (D2H2)conference, Arlington, VA, USA, (2006) April 2-4, pp. 79-82

[2] T. Bratan, M. Clake, R. Jones, A. Larkworthy and R. Paul, "Evaluation of the practical feasibility and acceptability of home monitoring in residential homes", J Telemed Telecare., vol. 11, Supplement 1, (2005), pp. 29-31.

[3] I. Korhonen, J. Parkka and M.Van Gils, "Health monitoring in the home of the future", IEEE Eng Med Bio Mag., vol. 22, no. 3, (2003), pp. 266-73.

[4] G. Pare, M. Jaana and C. Sicotte, "Systematic review of home telemonitoring for chronic diseases: the evidence base", J Am Med Inf Assoc, vol. 14, no. 3, (2007), pp. 269-77.

[5] K. Roback and A. Herzog, "Home informatics in healthcare: assessment guidelines to keep up quality of care and avoid adverse effects", Technol Health Care, vol. 11, no. 3, (2003), pp. 195-206.

[6] D. H. Stefanov, Z. Bien and W. C. Bang, "The smart house for older persons and persons with physical disabilities: structure, technology arrangements, and perspectives", IEEE Trans Neural Syst Rehab Eng., vol. 12, no. 2, (2004), pp. 228-50.

[7] L. Nashner, "A Systems Approach to Understanding and Assessing Orientation and Balance", NeuroCom International, Clackamas, OR, (1987).

[8] C. C. Lai, R. G. Lee, C. C. Hsiao, H. S. Liu and C. C. Chen, "A H-QoS-demand personalized home physiological monitoring system over a wireless multi-hop relay network for mobile home healthcare applications", J of Network and Computer Applications, vol. 32, (2009), pp. 1229-1241.

[9] S. O. O'Sullivan, “Assessment of motor function”, In: O'Sullivan SB, Schmitz TJ, eds. Physical Rehabilitation: Assessment and Treatment. 4rd ed. Philadelphia, PA: FA Davis, (2001), pp. 501-532.

[10] L. Nasher, “Adaptive reflexes controlling human posture”, Exp Brain Res, vol. 26, (1976), pp. 59.

[11]L. Nasher, "G. McCollum, The organization of human postural movements: a formal basis and experimental synthesis", Behavioral and Brain Sciences, vol. 8, (1985), pp. 135.

[12]F. Horak and L. Nashner, "Central programming of postural movements: adaptation to altered support-surface configuration", J Neurophysiol, vol. 55, (1986), pp. 1369.

[13]F. O. Back, C. Wall 3rd, H. E. Rockette Jr and R. Kitch, "Normal subject postural sway during the Romberg test", Am J Otolaryngol, vol. 3, (1982), pp. 309-18.

[14] J. S. O, M. H. Lee, M. J. Lim and K.Y. Lee, "A Study of the Health Monitoring System for u- Healthcare", The Journal of IWIT, vol. 9, no. 4, (2009), pp. 9-15.

[15] K. J. Lee, S. W. Park, "Patient Classification Scheme for Patient Information Management in Hospital U-Healthcare System", The Journal of IWIT, vol. 10, no. 3, (2010), pp. 131-137. 
[16] S. H. Lee and M. J. Lim, "Implementation of U-Healthcare Environment for Patient Recognition Applied Algorithms of Extracting Face Feature Points", The Journal of IWIT, vol. 9, no. 4, (2009), pp. 53-57.

[17] M. Gresy, "Stability of the head: studies in normal subject and in patients with labyrinthine disease", head tremor, and dystonia, Mov. Disord., vol. 2, (1987), pp. 165-185.

[18] R. Johansson and M. Magnusson, "Human postural dynamics", Crit. Rev. Biomed. Eng., vol. 18, (1991), pp. 413-437.

[19] S. Park, F. B. Horak and A. D. Kuo, "Postural feedback responses scale with biomechanical constraints in human standing", Exp. Brain Res., vol. 154, (2004), pp. 417-427.

[20] M. Samson and A. Crowe, "Intra-subject inconsistencies in quantitative assessments of body sway", Gait Posture, vol. 4, (1996), pp. 252-257.

[21] S. W. Franklin and S. E. Rajan, "Personal Area Network for Biomedical Monitoring Systems Using Human Body as a Transmission Medium", International Journal of Bio-Science and Bio-Technology, vol. 2, no. 2, (2010), pp. 23-28.

[22] Y. M. Han, "Bioworks: A Workflow System for Automation of Bioinformatics Analysis Processes", International Journal of Bio-Science and Bio-Technology, vol. 3, no. 4, (2011), pp. 59-68.

[23] C. H. Lee, "Biomechanical Analysis of the Physical Effects of Riding the X-lider", International Journal of Bio-Science and Bio-Technology, vol. 3, no. 4, (2011), pp. 69-78.

[24] J. L. Kim and M. J. Lim, "Estimating of Bio signal compound system", Advanced and Applied Convergence Letters, vol. 1, (2013), pp. 27-29.

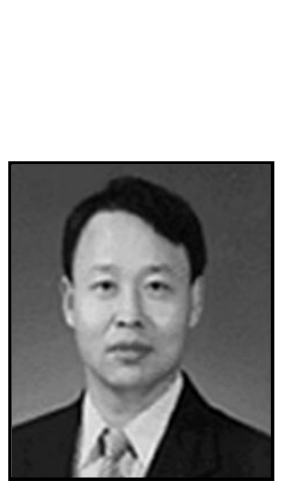

\section{Authors}

\section{Jeong-Lae Kim}

He received his B.S. degree in Bio-medical Engineering at Yonsei University in 1983, M.S. degrees in Electric Engineering at Konkuk University in 1989, and certificate program Ph.D. degrees in communication at KAIST in 1996, and Ph.D. degrees in biomedical Engineering at Yonsei University in 2011, South Korea. He joined Eulji University, South Korea, where he is now a professor in the department of Biomedical Engineering. He is a head of department of equipment management and bi-medical electronic instrument in Bio-Meditech Regional Innovation Center at Eulji University. He had worked in KOSOMBE (Korea Society Medical and Biological), South Korea as a researcher of data information \& processing department from 1983 until now. His research interests include Medical image communication, Bio-physical signal communication, and Bio-sensor system.

\section{Myung-Jae Lim}

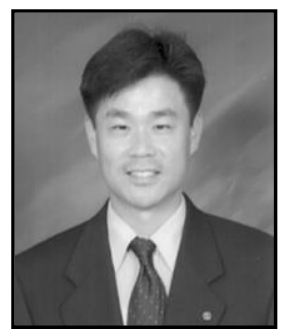

$\mathrm{He}$ received his B.S. degree in Computer Science at Chung-Ang University in 1986, M.S. degrees in software Engineering at Chung-Ang University in 1989, and Ph.D. degrees in software Engineering at Chung-Ang University 1998, South Korea. He joined Eulji University, South Korea, where he is now a professor in the department of Medical IT Marketing. His research interests include u-Healthcare system, Information Retrieval, Social Network service, and Big Data processing etc. He is now on the editorial staff of a Korea Information Processing society (KIPS) and director of the Institute of Internet, Broadcasting and Communication (IIBC). 